\title{
Immunological Aspects of Malignant Gliomas
}

\author{
Or Cohen-Inbar, Menashe Zaaroor
}

\begin{abstract}
Glioblastoma Multiforme (GBM) is the most common malignant primary brain neoplasm having a mean survival time of $<24$ months. This figure remains constant, despite significant progress in medical research and treatment. The lack of an efficient anti-tumor immune response and the micro-invasive nature of the glioma malignant cells have been explained by a multitude of immunesuppressive mechanisms, proven in different models. These immune-resistant capabilities of the tumor result in a complex interplay this tumor shares with the immune system. We present a short review on the immunology of GBM, discussing the different unique pathological and molecular features of GBM, current treatment modalities, the principles of cancer immunotherapy and the link between GBM and melanoma. Current knowledge on immunological features of GBM, as well as immunotherapy past and current clinical trials, is discussed in an attempt to broadly present the complex and formidable challenges posed by GBM.
\end{abstract}

RÉSUMÉ: Aspects immunologiques des gliomes malins. Le glioblastome multiforme (GBM) est le plus fréquent des néoplasmes cérébraux primaires malins. La survie moyenne est de moins de 24 mois et demeure inchangée malgré les progrès importants réalisés par la recherche médicale et les essais thérapeutiques. L'absence de réponse immunitaire anti-tumeur efficace et la nature micro-invasive des cellules malignes du gliome ont été expliquées par une multitude de mécanismes immunosuppresseurs, démontrés dans différents modèles expérimentaux. L'immunorésistance de la tumeur donne lieu à une interaction complexe entre la tumeur et le système immunitaire. Nous présentons une courte revue de l'immunologie du GBM et nous discutons de ses caractéristiques anatomopathologiques et moléculaires uniques, des modalités actuelles de traitement, des principes de l'immunothérapie du cancer et du lien entre le GBM et le mélanome. Nous exposons les connaissances actuelles sur les caractéristiques immunologiques du GBM ainsi que les essais thérapeutiques antérieurs et actuels d'immunothérapie, afin d'esquisser quels sont les défis considérables et complexes que pose le GBM.

Keywords: Anergy, Astrocytromas, Checkpoint inhibitors, Cytokine Modulation, Dendritic-Cell vaccination, Glioblatoma-Multiforma, Glioma, Immuno-Resistance, Immunotherapy, Neuroimmunology, Neuro-oncology - Surgical

doi:10.1017/cjn.2016.34

Can J Neurol Sci. 2016; 43: 494-502

\section{Pathological and Molecular Features OF GBM}

Astrocytoma (a subtype of gliomas - glial cell originated tumors) is graded on a scale ranging from the indolent benign grade-I astrocytoma to low grade (II) and to malignant astrocytoma grade III-IV. Grade-IV Astrocytoma or Glioblastoma Multiforme (GBM) is the most malignant astrocytoma in adults. Glioblastoma Multiforme is highly age specific; the incidence for the population younger than 14 years of age is $0.2 .^{1}$ This formidable entity is both the most common and the most malignant glioma in adults, suspected to arise from astrocytes. It usually presents as a unilateral, solitary tumor of the cerebral hemispheres. Its necrotic center may be partially delineated at gross examination, but infiltrating glioma cells can be easily identified microscopically well beyond the apparent gross tumor boundaries. Glioblastoma Multiforme is characterized histologically, like other high grade malignancies, by cellular atypia, mitoses, microvascular proliferation and necrosis. Primary GBM typically develops in patients in their sixth decade and beyond, while secondary GBM tends to arise in younger people ( $<45$ years) through malignant progression from a diffuse astrocytoma World Health Organization (WHO) grade II-III.
The classical histological characterization of GBM resulted in somewhat of a wastebasket category. We now recognize multiple molecular subsets of GBM (Table 1). Current 2007 WHO classification recognizes three major GBM variants, of which the classical form is further distinguished by DNA-chip expression patterns (based on genetic differences) and immunohistochemical (IHC) features (Table 1). Emerging GBM variants having very different prognostic horizons is further proof to the heterogeneity of the GBM definition and obsolete past classification tools. To further add to the confusion, different genetic, and IHC prognostic markers such as the bRAF status, epidermal growth factor receptor (EGF-R) expression pattern, methylation pattern etc., impose further classification onto existing systems. Table 1, presenting the WHO classical forms and emerging variants, does

From the Department of Neurological Surgery (OC, MZ), Rambam Health Care Center; Molecular Immunology Laboratory (OC, MZ); Faculty of Medicine (OC, MZ), Technion Israel Institute of Technology, Haifa, Israel; Department of Neurological Surgery and Gamma-Knife Radiosurgical Center (OC), University of Virginia Health Care Center, USA.

Received August 21, 2015. Final Revisions Submitted December 4, 2015. Date OF ACCEPTANCE February 8, 2016.

Correspondence to: Or Cohen-Inbar, 137 Yellowstone Drive, Charlottesville, VA 22903, USA. Email: oc2f@virginia.edu 
Table 1: Characteristics of Established GBM Tumor Variants

\begin{tabular}{|c|c|c|c|c|}
\hline GBM variant & \multicolumn{3}{|r|}{ Morphological features } & \multirow{6}{*}{$\begin{array}{c}\text { Mean OS } \\
12.7-21.7 \text { months }\end{array}$} \\
\hline \multirow[t]{7}{*}{$\begin{array}{l}\text { WHO defined } \\
\text { GBM variants }\end{array}$} & \multirow[t]{5}{*}{ Classic GBM } & $\begin{array}{l}\text { Primary vs. } \\
2^{\text {nd }}\end{array}$ & \multirow{5}{*}{$\begin{array}{l}\text { Infiltrating, pleomorphic, hyperchromatic cells with glassy, astrocytic } \\
\text { cytoplasm. Frequent presence of pseudopalisading necrosis, neo } \\
\text { epithelialization, mitotic figures, and hypercellularity. }\end{array}$} & \\
\hline & & Proneural & & \\
\hline & & Mesenchymal & & \\
\hline & & Classic & & \\
\hline & & Neural & & \\
\hline & Gliosarcoma & $\begin{array}{l}\text { GBM features } \\
\text { laminin, col } \\
\text { chymotryps }\end{array}$ & $\begin{array}{l}\text { heterogeneous sarcomatous / mesenchymal, differentiation staining for reticulin, } \\
\text { type IV, procollagen type III, fibronectin, vimentin, } \alpha 1 \text {-antitrypsin, and }\end{array}$ & 4-11.6 months \\
\hline & Giant cell GBM & GBM features & prominent multinucleated giant cells and lymphocytic infiltration. & 13 months \\
\hline $\begin{array}{l}\text { Emerging GBM } \\
\text { variants }\end{array}$ & $\begin{array}{l}\text { Fibrillary / epithelial } \\
\text { GBM }\end{array}$ & $\begin{array}{l}\text { GBM features } \\
\text { glands stain } \\
\text { pCEA, cyto }\end{array}$ & $\begin{array}{l}\text { fibrillary/ epithelial differentiation showing the formation of squamous nests and } \\
\text { or EMA, cytokeratin CAM 5.2, E-cadherin, cytokeratin AE1/AE3, cytokeratin 7, } \\
\text { in 5/6 and cytokeratin } 20 .\end{array}$ & 7 Months \\
\hline & Small cell astrocytoma & $\begin{array}{r}\text { Features of GH } \\
\text { cytoplasm, }\end{array}$ & $\begin{array}{l}\text { long with monomorphic proliferation of cells with small nuclei, limited } \\
\text { d interlaced stroma, mild hyperchromasia,and scant mitotic index. }\end{array}$ & 6-14.3 Months \\
\hline & Oligodendroglial & Features of GF & long with oligodendroglial features. & 19-26 Months \\
\hline & GBM with PNET & $\begin{array}{r}\text { GBM features } \\
\text { undifferenti } \\
\text { Wright neur }\end{array}$ & $\begin{array}{l}\text { PNET-like areas showing hypercellularity, minimal fibrillary background, small } \\
\text { cells with scant cytoplasm, oval-round hyperchromatic nuclei, and Homer- } \\
\text { tic rosettes staining for S-100, synaptophysin, NeuN, and NFP. }\end{array}$ & 44 Months \\
\hline & $\begin{array}{r}\text { Gemistocytic } \\
\text { astrocytoma }\end{array}$ & $\begin{array}{r}\text { GBM features } \\
\text { displaced nı }\end{array}$ & gemistocytes characterized by glassy, non-fibrillary cytoplasm and peripherally & 64 months \\
\hline & $\begin{array}{l}\text { Granular cell } \\
\text { astrocytoma }\end{array}$ & $\begin{array}{l}\text { Features of GE } \\
\text { shapes, and }\end{array}$ & $\begin{array}{l}\text { along with abundant granular cells with large distinct cell borders, round to oval } \\
\text { dant eosinophil granular cytoplasm staining for GFAP, CD68, EMA, and S100. }\end{array}$ & 7.6 months \\
\hline & $\begin{array}{l}\text { Pediatric HGG diffuse } \\
\text { pontine. }\end{array}$ & Resembles GB & xcept for presence in pediatric patients. & 2 years is $10-30 \%$ \\
\hline
\end{tabular}

WHO - World Health Organization, OS - overall survival, PNET - primitive neuroectodermal tumor, GFAP - glial fibrillary acidic protein,

EMA - Epithelial Membrane Antigen, CAM - cell adhesion molecule, pCEA - polyclonal antibody against carcinoembryonic antigen, NFP - neurofilament protein, HGG - high-grade glioma. ${ }^{2-3}$

not take into account these markers, which are very important in determining prognosis, and thus is incomplete. The dissection into this obscure general term, identifying clinical entities with very different clinical behavior and prognosis will undoubtly result in redefining and reclassifying this disease in the near future. ${ }^{2-3}$

\section{Current Treatment and Prognosis of GBM}

The most prevalent brain tumor, GBM is associated with a dismal median overall survival of one to two years and a five-year survival rate of less than $10 \% .^{4-6}$ In the 1930 s, Walter Dandy reported recurrence of contralateral gliomas even after a hemispherectomy, thus illustrating how infiltrative these tumors are. Current day, first-line treatment for GBM patients includes a combination of debulking surgery, chemotherapy and radiotherapy. ${ }^{5}$ A multimodality regimen of radiotherapy, Temozolomide and Gliadel (carmustine-loaded biodegradable polymers) shows the highest mean overall survival of 20 months $^{7-8}$ and established current day clinical treatment of GBM. Yet, even this combination has only modestly improved overall survival. ${ }^{9}$

$O^{6}$-Methylguanine-DNA methyltransferase (MGMT) is an important repair enzyme that contributes to the resistance of tumors against alkylating agents such as carmustine or Temodar. $O^{6}$-Methylguanine-DNA methyltransferase promoter methylation silences the gene, thus decreasing DNA repair activity and increasing the susceptibility of the tumor cells to carmustine or Temodar. Temodar (temozolomide) puts methyl groups to guanine, a process halted in part by the repair enzyme product of the MGMT gene. Temodar is currently used for the treatment of GBM regardless of its MGMT promoter methylation status. Consequently, glioblastoma ultimately relapses in almost all patients, and none of the current treatments can effectively prolong survival after relapse. ${ }^{10}$ This dismal prognosis, resulted in considerable interest directed towards the development of new therapeutic approaches for this disease. ${ }^{11}$

Immunotherapy has come to the fore of anti-cancer therapy with the Food and Drug Administraton (FDA) approval of cytokine based therapy with interleukin-2 in 1998 for malignant melanoma, the introduction of sipuleucel-T in 2010 as the first antigen-specific vaccine for treatment resistant prostate cancer, the approval of Ipilimumab, the first checkpoint inhibitor for advanced melanoma in 2011. ${ }^{12-13}$ While some cancer types have been amenable to immunotherapeutic approaches, GBM has not received similar clinical successes, likely due to its poor immunogenicity, few characterized cancer antigens, and for its location in the immunologically distinct central nervous system (CNS). ${ }^{14}$ We present a short review at the obstacles and ongoing attempts in developing a potent immunotherapeutic approach and tool to battle GBM. 


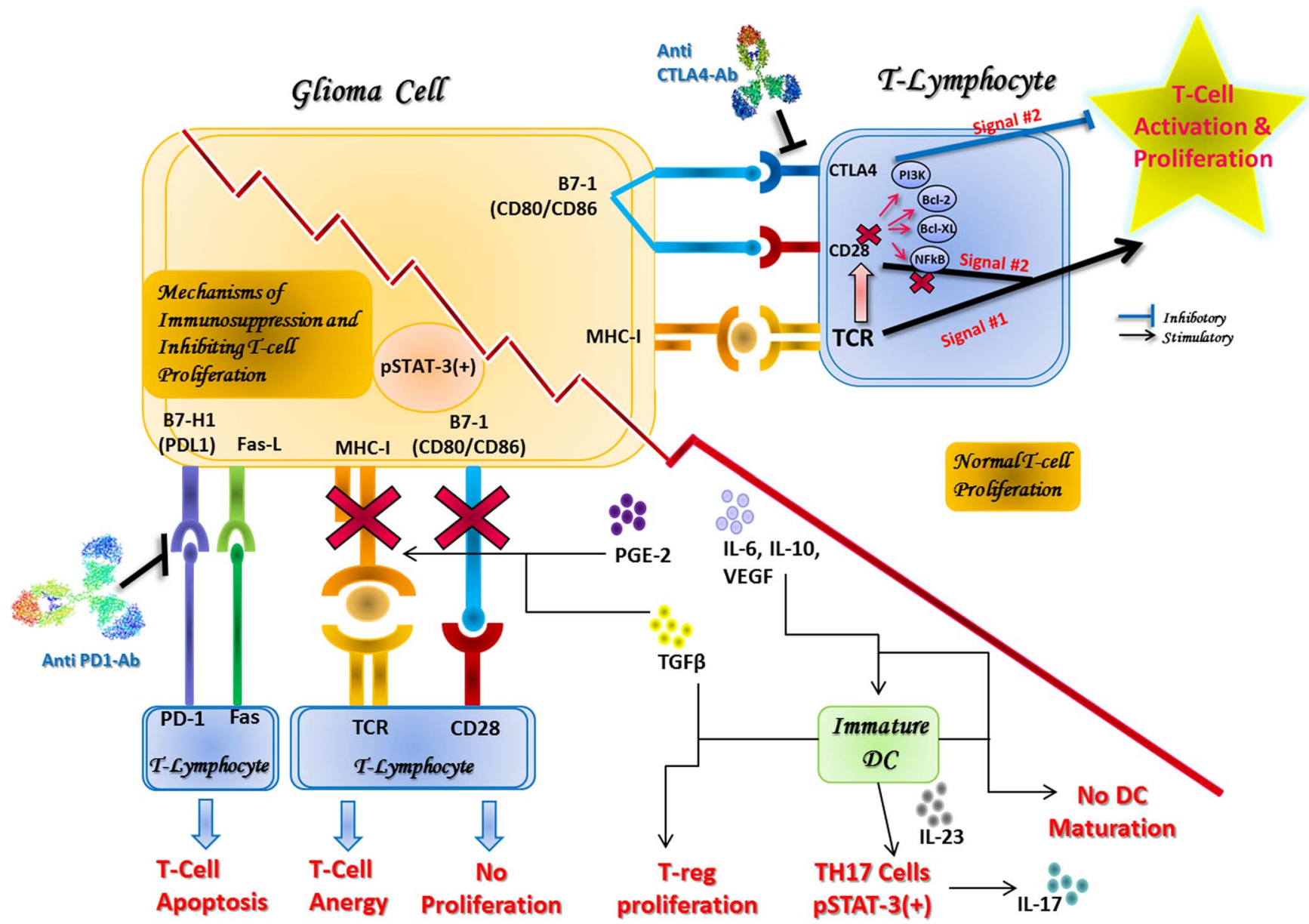

Figure 1: Normal T cell proliferation and mechanisms of glioma cell immunoresistance. Top Right: Normal T cell proliferation. T cell proliferation, differentiation, and cytokine release require two separate signal mechanisms. The first signal involves $T$ cell receptor-mediated recognition of tumor antigen presented by MHC I, which is located on the tumor cell. A second costimulatory signal involves B7 ligand, located on the tumor cell, binding to CD28, a receptor on the T cell. Both of these signals stimulate a variety of intracellular signaling pathways, which lead to upregulated activity of regulator proteins such as nuclear factor- $\kappa B, B C l-2$, and PI3K. These signals promote $T$ cell activation. However, other ligand-receptor binding pairs can inhibit these cascades and restrict $T$ cell activation. These inhibitory checkpoints include B7 binding to CTLA-4 and B7-H1 (PD-L1) binding to PD-1. Anti-CTLA-4 antibodies (ipilimumab) and anti-PD-1 antibodies facilitate T cell activation by obstructing inhibitory checkpoint processes. Bottom Left: Mechanisms of immunosuppression. glioma cells secrete factors leading to an immunosuppressive tumor microenvironment. Transforming growth factor B (TGFB) and prostaglandin E-2 downregulate the expression of MHC, restricting antigen presentation and $T$ cell proliferation. Interleukin-6. interleukin-10 and vascular endothelial growth factor are potent STAT-3 activators, leading to the proliferation of immature dendritic cells $(D C s)$ that are not able to function as APCs. These immature DCs also secrete TGFB which aid in the proliferation of immunosuppressive T-reg cells and STAT-3 positive TH17 cells. Glioma cells downregulate MHC on their surface leading to the decreased antigen presentation and decreased $T$ cell proliferation. Downregulation of B7 works via a similar mechanism in that the Costimulatory signal is lost preventing T cell proliferation. Increased expression of B7-H1 and FasL act as proapoptotic signals for T cells. ${ }^{69,97,98}$

\section{Immunology Background - The Role of Signal-1 and Signal-2 and the Immune Synapse}

T cells that have graduated the thymic selection processes and successfully mounted a T-cell receptor (TCR) are defined as naïve $\mathrm{T}$ cells. To elicit their effector functions, they must undergo a multi-step priming process. The initial interaction during activation of a naïve $\mathrm{T}$ cell is the binding of the TCR with the MHC-peptide complex [MHC class I for cytotoxic T-lymphocytes (CTLs) or class II for T-helper cells]. ${ }^{15}$ This initial crucial step is than stabilized by the binding of CD4 or CD8 co-receptors molecules (in T helper cells or CTLs, respectively) to the MHC molecule (termed as Signal-1). Signal-1 events are accompanied by the interaction of several other receptors (termed as co-stimulatory and co-inhibitory signals) molecules (a process termed as signal-2). Signal-2 establishes the TCR signaling cascade and inducing differentiation and activation of the T-cell (Figure 1). A signal-1 interaction that lacks signal 2 will fail to elicit T-cell activation and differentiation. Different co-stimulatory (e.g. CD28) and co-inhibitory (e.g. CTLA-4) signal-2 molecules drive differentiation to different avenues, ranging from a potent Th1 based anti-tumor response (in case of CD28 activation), to anergy and even apoptosis (in case of CTLA-4 or Fas activation). ${ }^{16}$

The contact area between the $\mathrm{T}$ cell surface receptors and the antigen-presenting cells or target cell's surface receptors has been termed as the immunological synapse (Figure 1). Several studies 
have estimated that $\mathrm{T}$ cell activation requires as little as a single MHC-peptide complex. ${ }^{17-18}$ Recent evidence supports the concept that a single MHC-peptide complex can activate CD4+ $\mathrm{T}$ cells, whereas binding $10 \mathrm{MHC}$-peptide complexes are needed for synapse formation. The binding of more than 60 to 70 MHC-peptide complexes can activate the $\mathrm{T}$ cells without co-stimulatory receptors interaction (over-ruling the need for signal 2). Such sensitivity was also demonstrated for CTLs. ${ }^{19}$

\section{The Principles of Cancer Immunotherapy}

The categorization of the CNS as an immune privileged site has perhaps retarded the development of immunotherapies for brain tumours, with the temptation to anticipate ineffective immune function in the brain. ${ }^{20}$ Different features of the CNS were identified that were proposed to explain this apparent lack of immune reactivity. These included the presence of the blood-brain barrier (BBB), low MHC expression in the brain parenchyma, the absence of organized lymphatic drainage and a lack of dendritic cells in the normal brain parenchyma. Nevertheless, it is now apparent that immune reactions can and do occur in the CNS: autoimmune diseases of the CNS, ${ }^{21}$ immune responses to bacteria, neurotropic viruses ${ }^{22}$ and parasites $^{23}$ and anti-tumor responses, as discussed.

The first requirement for an effector $\mathrm{T}$ cell is that it must reach its target (i.e. the tumor). This problem of adequate tumor infiltration is relevant to all solid cancers, more-over in the case of tumors located in the brain parenchyma, in which case the T-cell must also penetrate through the blood brain barrier formed by the tight junctions between the endothelial cells, basement membrane and astrocytic podocytes. ${ }^{24}$ Yet, for spontaneous malignant astrocytoma in humans, the integrity of the BBB was shown to be locally compromised and tumor-induced angiogenesis does not incorporate $\mathrm{BBB}$ characteristics. ${ }^{20}$ In conclusion, the particular requirements for mounting an immune responses against tumors in the CNS include several steps: (1) Effector T cells must penetrate the brain parenchyma before reaching the tumor bed. (2) Target antigens must permit adequate discrimination of normal versus malignant tissue. (3) Tumor cells must express sufficient MHC molecule for direct specific CTL's effector response. (4) Brain inflammation must be regulated. (5) T-cells must retain their anti-tumor effector function during migration through the parenchyma and its resident cells. (6) Effector cell functionality must be retained during the encounter with the tumor cell.

In general terms, immunotherapy can be either active or passive. Active immunotherapy can be specific or non-specific. Passive immunity can be antibody based or cellular effector based. Active non-specific approaches have yielded potent immunological anti-tumor responses. One important example is the Bacillus Calmette -Guérin (BCG) vaccine. Examples of active specific approaches include immunization with specific tumor antigens or with peptide pulsed dendritic cells. These approaches are known to achieve meaningful clinical responses in a variety of tumors. Tumor antigens have been detected using $\mathrm{T}$ lymphocytes isolated from patients or by using SEREX (screening for auto-antibodies). Vaccines can be based on whole or lysed tumor cells, defined protein or peptide antigens, nucleic acids, heat shock proteins (Table 2).

The use of monoclonal antibodies (mAbs) and recombinant antibody fragments for passive specific or non-specific immunotherapy are in widespread use. Several mAbs were approved by the FDA for clinical use either as a monotherapy or in combination with other chemotherapy agents. Targeted therapies using mAbs include both unconjugated and conjugated monoclonal antibodies. Unconjugated antibodies can induce recruitment and activation of effector cells by different mechanisms [antibody dependent cellular cytotoxicity (ADCC), cell dependent cytotoxicity (CDC)], blocking the interaction between receptor-ligand or by inducing apoptosis. Conjugated antibodies are used for the delivery of radioisotopes, enzymes, toxins or drugs to the tumor. ${ }^{25-26}$

Passive cellular effector based immunotherapy include techniques such as adoptive cell transfer, which includes isolation of tumor infiltrating lymphocytes (TIL's), their ex-vivo expansion and administration back to the patient. This simple approach is showing promising results in melanoma treatment. These cells can be given together with systemic cytokines, such as interleukin-2, or transfected with cytokine genes, such as tumour necrotic factor. Another variation to this approach involves activation of peripheral blood mononuclear cells ex vivo [lymphokine-activated killer (LAK)] cells prior to reinjection. Evolving tetramer technology has made it possible to select CD8 + T cells from the peripheral blood having high affinity for some particular peptide epitopes. ${ }^{27}$

\section{The Link between Glioblastoma and Melanoma}

Glial cells and melanocytes are both originated from the neuro-ectoderm and, as such, share embryonic antigens. Although melanoma associated antigens (MAA) are well characterized, glial derived antigens are less studied. Melanogenesis related proteins are characteristic of melanoma yet are found also in neuroectodermal originated organs such as the cochlea, the eye, and glial cells. This antigen resemblance was also proven between melanomas and GBM. $^{28-29}$ In addition, melanoma associated differentiation antigens (DA) such as MART-1, Gp-100, Tyrosinase, Gage, and MAGE have been proven to be present in glioblastoma and other neuro ectodermal originated cell lines and tumors. ${ }^{30}$ Glioblastoma multiforme specific antigens are poorly characterized. Most studies characterizing GBM associated antigens have used detection methods such as detecting messenger RNA levels, intracellular protein levels and T-cell activity assays, ${ }^{30-32}$ proving only the mere presence of intracellular antigens, or T-cell activity against a certain examined peptide, derived from intracellular antigens. The presence of an intracellular protein was shown not to correlate with its HLA antigenic presentation, which is dependent, among other, on stability and intracellular processing. ${ }^{30-32}$ These features, inter alia, explain both the rational and the relative success in implementing anti-melanoma immunotherapeutic approaches (such as utilizing the immune-stimulating effect of anti-CTLA4 and anti-PD1 antibodies Ipilimumab and pembrolizumab) in the treatment of high grade gliomas. It also sets the rational for employing targeted therapy (monoclonal antibodies, MHC-tetramers etc.) against melanoma associated differentiation antigens (DA) for GBM patients.

\section{The Immunology of GBM}

As with systemic neoplasia, the cause of death from GBM is not always clear. Although some patients succumb to the mass effect and subsequent cerebral herniation, others die without a clear evidence of significant mass effect. ${ }^{33}$ Because these tumors rarely metastasize outside the $\mathrm{CNS}$, the typical progressive neurological deterioration and eventual demise is most likely 
Table 2: Selected Immunotherapeutic Trials for Malignant Gliomas

\begin{tabular}{|c|c|c|c|c|c|}
\hline \multicolumn{2}{|l|}{ Reference } & \multirow{2}{*}{$\begin{array}{l}\text { No. of } \\
\text { Patients }\end{array}$} & \multicolumn{2}{|c|}{ Immunological response } & Clinical response \\
\hline \multirow[t]{3}{*}{ Dendritic Cells } & 70 & & \multicolumn{2}{|c|}{$\begin{array}{l}\text { CTLs and memory T-cells were found in recurrent tumor } \\
\text { mass. }\end{array}$} & MS 455 days \\
\hline & 71 & $\mathrm{~N}=12$ & \multicolumn{2}{|c|}{$\begin{array}{l}\text { Cytotoxicity against autologous tumor cells. CTLs were } \\
\text { found in recurrent tumor mass. }\end{array}$} & $\begin{array}{l}\text { Median TTP } 19.9 \text { months }(\mathrm{p}=0.028) \text {, MS } 35.8 \text { months } \\
\quad(\mathrm{p}=0.006)\end{array}$ \\
\hline & 72 & $\mathrm{~N}=18$ & \multicolumn{2}{|c|}{$\begin{array}{l}\text { EGFRvIII positive GBM included. } 825 \text { of recurrent tumors } \\
\text { lost their EGFRvIII expression. }\end{array}$} & MS 26 months $(\mathrm{p}=0.001)$ \\
\hline \multirow{3}{*}{$\begin{array}{l}\text { Autologous Tumor } \\
\text { Cells }\end{array}$} & 73 & $\mathrm{~N}=11$ & \multicolumn{2}{|c|}{ Local skin reaction. } & MS 46 weeks. \\
\hline & 74 & $\mathrm{~N}=23$ & \multicolumn{2}{|c|}{$\begin{array}{l}\text { Delayed type hypersensitivity, increased memory T-cells } \\
\text { and CD + T-cells in recurrent tumors. }\end{array}$} & Median PFS 40 weeks, MS 100 weeks \\
\hline & 75 & $\mathrm{~N}=12$ & \multicolumn{2}{|r|}{ 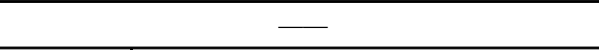 } & CR-1, PR-1, MR-2, MS 10.7months \\
\hline \multirow[t]{15}{*}{ Cytokine Modulation } & 76 & $\mathrm{~N}=145$ & TGF- $\beta$ & - & MS 39.1 months $(10 \mu \mathrm{M}$ dose $), 35.2$ months ( $80 \mu \mathrm{M}$ dose $)$ \\
\hline & 77 & $\mathrm{~N}=9$ & IL-2 & - & Tumor enhancement on MRI unchanged \\
\hline & 78 & $\mathrm{~N}=9$ & IL-2 & - & PR-1 \\
\hline & 79 & $\mathrm{~N}=12$ & IL-2 & Increased inflammatory infiltrate in tumors. & PR-2, MR-4, OS 58\% (6 months) \\
\hline & 80 & $\mathrm{~N}=31$ & $\mathrm{IFN}-\gamma$ & - & PR-3, no difference in MS \\
\hline & 81 & $\mathrm{~N}=40$ & $\mathrm{IFN}-\gamma$ & - & No difference in MS or OS \\
\hline & 82 & $\mathrm{~N}=29$ & IFN- $\beta$ & - & PR-2 \\
\hline & 83 & $\mathrm{~N}=20$ & IFN- $\beta$ & $\begin{array}{l}\text { IFN- } \beta \text { treatment showed no growth } \\
\text { suppression. }\end{array}$ & - \\
\hline & 84 & $\mathrm{~N}=7$ & IFN- $\beta$ & - & No response \\
\hline & 85 & $\mathrm{~N}=35$ & IFN- $\alpha$ & - & MS 13.3 months \\
\hline & 86 & $\mathrm{~N}=275$ & $\mathrm{IFN}-\alpha$ & - & No difference in survival \\
\hline & 87 & $\mathrm{~N}=9$ & IFN- $\alpha$ & - & CR-2 \\
\hline & 88 & $\mathrm{~N}=12$ & IL-4 & Positive Elipsot assay. & No difference in PFS. \\
\hline & 89 & $\mathrm{~N}=9$ & IL-4 & - & Survival >18 months $(\mathrm{n}=1)$ \\
\hline & 90 & $\mathrm{~N}=15$ & IL-12 & - & PR-1, mixed response-1 \\
\hline HSP & 53 & $\mathrm{~N}=12$ & \multicolumn{2}{|c|}{-} & MS 10.5 months \\
\hline \multirow[t]{5}{*}{ LAKs } & 78 & $\mathrm{~N}=9$ & & - & PR-1 \\
\hline & 91 & $\mathrm{~N}=9$ & \multicolumn{2}{|c|}{ Cultured LAK cells lysed cultured glioma cells $(\mathrm{N}=6)$. } & Slight clinical (not radiological) improvement \\
\hline & 92 & $\mathrm{~N}=20$ & \multicolumn{2}{|c|}{-} & MS - 63 weeks \\
\hline & 93 & $\mathrm{~N}=19$ & \multicolumn{2}{|r|}{-} & CR-1, PR-1, MS- 15 weeks \\
\hline & 94 & $\mathrm{~N}=40$ & \multicolumn{2}{|r|}{-} & MS 17.5 months \\
\hline \multirow[t]{2}{*}{ CTLs } & 95 & $\mathrm{~N}=4$ & \multicolumn{2}{|r|}{-} & PR-3 \\
\hline & 96 & $\mathrm{~N}=12$ & \multicolumn{2}{|r|}{-} & PR-4 \\
\hline
\end{tabular}

LAKs - Lymphokine activated killer cells, CTLs - Cytotoxic T-lymphocytes, HSP - heat shock proteins, EGFR - epidermal growth factor receptor, TGF - transforming growth factor, IL - interleukin, IFN - interferon, MS - median survival, PFS - progression free survival, TTP - time to progression, $\mathrm{CR}$ - complete response, $\mathrm{PR}$ - partial response, MR - minimal response, OS - overall survival.

caused by injury to the brain mediated by unknown mechanisms. Although these tumors remain rapidly fatal, some long-term survivors have been reported (Table 1).

Patients with GBM exhibit impaired antitumor immunity and impaired systemic immunity leading to bacterial infections. The former relies on local cellular immunity mediated by the $\mathrm{Th}_{1}$ subset of helper T cells, while the latter relies on systemic humoral immunity mediated by the $\mathrm{Th}_{2}$ subset of helper T cells. ${ }^{34-35}$ Past empiric observations reported that patients with GBM who experienced a postoperative cranial wound infection exhibited longer survival. This observation was initially attributed to bacterial lipopolysaccharide (LPS) eliciting a nonspecific immune response which also targets the tumor. Since these observations a plethora of studies focused on characterizing the immunological roles GBM have been conducted.

Patients harboring GBM were shown to exhibit low number of circulating T-cells, rendering them prone to viral infections, abnormal delayed type hypersensitivity and impaired cytotoxic T-cell reaction. ${ }^{36}$ Fecci et $\mathrm{al}^{37}$ reported a greater than 2.5 -fold increase in the proportion of circulating regulatory $\mathrm{T}$ cells $(\mathrm{CD} 4+\mathrm{FoxP}+\mathrm{T}$ cells $)$ in patients with newly-diagnosed or recurrent GBM. This effect was noted not be related to the 
co-administration of glucocorticoids. ${ }^{37}$ The frequency of $\mathrm{T}$ regulatory cells (T-regs) was shown to correlate directly with in vitro suppression of $\mathrm{T}$ cell activation. ${ }^{38-39}$ In contrast to the evidence documenting the expansion of T-regs within the peripheral $\mathrm{T}$ cell compartment, it remains a matter of some debate as to whether T-regs are found at increased frequency within TIL from patients with GBM. ${ }^{37-39}$

The immunosuppressive effect the tumor imparts can be demonstrated both locally and systemically. A multitude of immunosuppressive mechanisms were suggested and proven in different models, trying to capture and define the complex interplay this tumor shares with the immune system. Multiple genetic pathways are known to be altered in GBM, including $\mathrm{p} 16 / \mathrm{pRb} /$ CDK4, p53/ MDM2/ p14ARF, EGF-R [with unique variants like the EGFRvIII emerging in some tumors, responsive to Erlotinib (EGF-receptor tyrosine kinase inhibitor)], platelet-derived growth factor receptor (PDGF), and PI3-kinase/PTEN. ${ }^{40-42}$ The most common genetic alteration in GBM tumors is the loss of heterozygosity of chromosome \#10, occurring in $80 \sim 95 \%$ of these tumors. ${ }^{34-35,40-42}$ Interestingly, disruption of two of these tumor suppressor genes found on chromosome $10 \mathrm{q}$ may mediate a decrease in tumor cell immunogenicity (i.e. DBMT1, PTEN). DBMT1 is a candidate tumor suppressor for brain, gastrointestinal, and lung cancer. Phosphatase and tensin (PTEN) homologue deleted in chromosome 10q23.3) is an inhibitor of the PI3 kinase-signalling pathway, whose disruption may increase expression of immunosuppressive protein $\mathrm{B} 7-\mathrm{H} 1$ and also increases $\mathrm{Th}_{2}$ type cytokines release, ${ }^{40-42}$ supporting the evolution of anergy and tolerance to the tumor (Figure 1).

Another mechanism suggested is the tumor's ability to down-regulate or express low levels of class-I MHC, ${ }^{43}$ hiding its existence from the cellular arm of the immune system, as well as the aberrant expression of non-classical MHC class I molecule (class Ib) termed HLA-G, structurally related to classical MHC class Ia (HLA-A, -B, -C), that has been attributed functions as an antigen-presenting molecule but also immune regulatory functions. HLA-G expression, render cells highly resistant to direct alloreactive lysis, inhibits the alloproliferative response, and prevents efficient priming of cytotoxic $\mathrm{T}$ cells. The inhibitory effects of HLA-G are directed against CD8 expressing and CD4 expressing $\mathrm{T}$ cells but appear to be NK (natural killer) cell independent. $^{44-45}$

Another mechanism involves the upregulation of anti-apoptotic proteins (IAP's - inhibitors of apoptosis), such as the survivin protein $^{46}$ by the GBM tumor cells, rending these cells immortal. Finally, parallel and in consort with all mechanisms mentioned, the tumor microenvironment is characterized by its immunosuppressive nature. ${ }^{47}$ The cytokines secreted, be it directly or indirectly by the GBM tumor cells, mediate immune-anergy and tumor proliferation (Interferon- $\gamma$, IL-10, TGF $\beta)^{36,48}$ The interplay between the different mechanisms stated is complex and largely unknown. A schematic representation of key mechanisms is presented in Figure 1.

\section{GBM Immunotherapy - Past trials}

Many immunotherapeutic approaches have been tested in order to facilitate cure or a meaningful clinical response. Clinically speaking, such approaches are incorporated into current treatment algorithms. The need for tissue diagnosis and for surgical debulking will likely always be a component of treatment, as will be some form of focused radiation (radiosurgery, intensitymodulated radiation therapy, external beam radiation therapy, etc.). Table 2 depicts some examples of clinical trials, based on immunological mediators and mechanisms, highlighting the preliminary response. One should note that, although different strategies have been employed through the years (Table 2), early studies did not employ combined treatments. Current surgical, radiotherapeutic and medical alkylating agents were not available early on and their failure may not necessarily imply conceptual failure. As described previously and presented in Figure 1, most immunological avenues have been harnessed in an attempt to circumvent the GBM induced anti-tumor immunosuppression. Dendritic cell vaccination, ${ }^{49}$ autologous formalin-fixed tumor vaccines,${ }^{50}$ cytokine gene therapy, ${ }^{51}$ adoptive cell transfer based therapies, ${ }^{52}$ cytokine modulation, lymphokine activated killer (LAK) cells based approaches and CTL based approaches previously discussed, are noted. Heat shock proteins based vaccines concept is based on evidence that these proteins are implicated in the activation of both innate and adaptive immune systems. Vaccines formulated from heat shock protein-peptide complexes, derived from autologous tumor, have been applied to the field of immunotherapy for glioblastoma. ${ }^{53-54}$ In general, although some encouraging clinical trials have been conducted, these are limited.

In the past five years, immunotherapy with immune checkpoint inhibitors has shown promise and clinical results in fighting tumors resistant to conventional therapies, such as melanoma and lung adenocarcinoma (non-small cell lung carcinoma, (NSCLC)) ${ }^{55-59}$ These compounds facilitate effective antineoplastic immune response by antibody mediated suppression of co-inhibitory receptors and pathways (co-inhibitory signal-2). This inhibition tilts the scales in favor of a potent CTL's activation, and not anergy as discussed. A key point in these modalities is the finding that immune checkpoint inhibitors can induce a deep and durable remission with an acceptable safety and side-effect profile. ${ }^{55-59}$ The FDA recently approved the two checkpoint inhibitors that target programmed cell death protein 1 (PD1) in late 2014 (pembrolizumab and nivolumab for metastatic melanoma), and nivolumab for non small-cell lung carcinoma (NSCLC) in early 2015 . $^{60-61}$ The first large phase-III trial of nivolumab in GBM patients (NCT02017717) was initiated in 2014 and initial results seem promising. ${ }^{11}$

\section{Future Directions}

Immunotherapy for GBM, be it passive or active and specific or non-specific, is being actively studied in preclinical models and translated to clinical trials. Combining immunotherapy modalities or treatment regimens involving both standard therapies and immunotherapies show promise as powerful anti-cancer therapies in GBM. A phase I clinical trial studying the effects of anti-PD-1 and anti-CTLA-4 combination therapy is currently recruiting for recurrent GBM and a number of studies of dendritic cell vaccines in recurrent and newly diagnosed GBM are also underway. A phase-2 study of concurrent radiation therapy, temozolomide and the histone deacetylase inhibitor (HDAC) valproic acid showed improved outcomes and merits further investigation. ${ }^{62}$ The combined use of multiple checkpoint inhibitors with other intracellular enzymes whose expression correlate to malignancy 
and checkpoint inhibition such as the Indoleamine 2,3 dioxygenase 1 (IDO) catabolic enzyme, has recently shown a survival advantage in a mouse model. ${ }^{63-64}$

Pioneering work done with TCR-like antibodies, ${ }^{65-68}$ MMP targeting, ${ }^{69}$ scorpion and spider toxin used targeting, ${ }^{69}$ in which a modular targeting moiety, consisting of a single chain antibody fragment $(\mathrm{ScFv})$ or another targeting peptide, linked via a flexible linker to an effector moiety holds great promise. The effector domain is an HLA-A2 molecule (human leukocyte antigen) bearing a highly immunogenic, viral peptide. This strategy enables recruitment and redirection of previously formed, highly potent memory CTLs to the tumor's milieu, thus presenting tumor cells as viral infected to the immune system.

It seems that in the fight against GBM, this challenge will be met through the use of a multidisciplinary combined treatment approach, utilizing the advantages offered by surgical debulking, focused radiation, alkylating agents, pro-inflammatory agents (such as checkpoint blockers) and T-cell recruitment to the tumor milieu, each harnessing different anti-tumor mechanism and working synergistically.

\section{Conflict of Interest Disclosure}

The author has no personal or institutional financial interest in drugs or materials in relation to this paper. Or Cohen-Inbar and Menashe Zaaroor do not have anything to disclose.

\section{REFERENCES}

1. Mao YM, Desmeules M, Semenciw RM, Hill G, Gaudette L, Wigle DT. Increasing brain cancer rates in Canada. CMAJ. 1991;145:1583-91.

2. Karsy M. Mechanisms of gliomagenesis and glioblastoma multiforme variants. Folia Neuropathol. 2012;50:301-21.

3. Habberstad AH, Lind-Landström T, Sundstrøm S, Torp SH. Primary human glioblastomas - prognostic value of clinical and histopathological parameters. Clin Neuropathol. 2012;31:361-8.

4. Buckner JC. Factors influencing survival in high-grade gliomas. Semin Oncol. 2003;30:10-4.

5. Stupp R, Mason WP, van den Bent MJ, et al. Radiotherapy plus concomitant and adjuvant temozolomide for glioblastoma. N Engl J Med. 2005;352:987-96.

6. DeAngelis LM. Brain tumors. N Engl J Med. 2001;344:114-23.

7. Chaichana KL, Zaidi H, Pendleton C, et al. The efficacy of carmustine wafers for older patients with glioblastoma multiforme: prolonging survival. Neurol Res. 2011;33:759-64.

8. McGirt MJ, Than KD, Weingart JD, et al. Gliadel (BCNU) wafer plus concomitant temozolomide therapy after primary resection of glioblastoma multiforme. J Neurosurg. 2009;110:583-8.

9. Nagasawa DT, Chow F, Yew A, Kim W, Cremer N, Yang I. Temozolomide and other potential agents for the treatment of glioblastoma multiforme. Neurosurg Clin N Am. 2012;23: 307-22.

10. Weller M, van den Bent M, Hopkins K, et al. EANO guideline for the diagnosis and treatment of anaplastic gliomas and glioblastoma. Lancet Oncol. 2014;s15:e395-403.

11. Preusser M, Lim M, Hafler DA, Reardon DA, Sampson JH. Prospects of immune checkpoint modulators in the treatment of glioblastoma. Nat Rev Neurol. 2015, Sep;11(9):504-14.

12. Drake CG. Prostate cancer as a model for tumour immunotherapy. Nat Rev Immunol. 2010;10:580-93.

13. Lipson EJ, Drake CG. Ipilimumab: an anti-CTLA-4 anti-body for metastatic melanoma. Clin Cancer Res. 2011;17:6958-62.

14. Patel MA, Pardoll DM. Concepts of immunotherapy for glioma. J Neurooncol. 2015;123:323-30.

15. Klein J, Sato A. The HLA system. First of two parts. N Engl J Med. 2000;343:702-9.

16. Schwartz RH. T cell anergy. Annu Rev Immunol. 2003;21:305-34.
17. Irvine DJ, Purbhoo MA, Krogsgaard M, Davis MM. Direct observation of ligand recognition by T cells. Nature. 2002;419:845-9.

18. Stefanova I, Dorfman JR, Germain RN. Self-recognition promotes the foreign antigen sensitivity of naive $\mathrm{T}$ lymphocytes. Nature. 2002;420:429-34.

19. Davis MM, Krogsgaard M, Huppa JB, et al. Dynamics of cell surface molecules during $\mathrm{T}$ cell recognition. Annu Rev Biochem. 2003;72:717-42.

20. Walker PR, Calzascia T, Dietrich PY. All in the head: obstacles for immune rejection of brain tumours. Immunology. 2002;107:28-38.

21. Hohlfeld R, Wekerle H. Immunological update on multiple sclerosis. Curr Opin Neurol. 2001;14:299-304.

22. Dörries R. The role of T-cell-mediated mechanisms in virus infections of the nervous system. Curr Top Microbiol Immunol. 2001;253:219-45.

23. Fischer HG, Bonifas U, Reichmann G. Phenotype and functions of brain dendritic cells emerging during chronic infection of mice with Toxoplasma gondii. J Immunol. 2000;164:4826-34.

24. Rubin LL, Staddon JM. The cell biology of the blood-brain barrier. Annu Rev Neurosci. 1999;22:11-28.

25. Harris M. Monoclonal antibodies as therapeutic agents for cancer. Lancet Oncol. 2004;5:292-302.

26. Zafir-Lavie I, Michaeli Y, Reiter Y. Novel antibodies as anticancer agents. Oncogene. 2007;26:3714-33.

27. Davis ID. An overview of cancer immunotherapy. Immunol Cell Biol. 2000;78:179-95.

28. Princiotta MF, Finzi D, Qian SB, et al. Quantitating protein synthesis, degradation, and endogenous antigen processing, Immunity. 2003;18:343-54.

29. Liu G, Ying H, Zeng G, Wheeler CJ, Black KL, Yu JS. HER-2, gp100, and MAGE-1 are expressed in human glioblastoma and recognized by cytotoxic T cells. Cancer Res. 2004;64:4980-6.

30. Zhang JG, Eguchi J, Kruse CA, et al. Antigenic profiling of glioma cells to generate allogeneic vaccines or dendritic cell-based therapeutics. Clin Cancer Res. 2007;13:566-75.

31. Saikali S, Avril T, Collet B, et al. Expression of nine tumour antigens in a series of human glioblastoma multiforme: interest of EGFRvIII, IL-13Ralpha2, gp100 and TRP-2 for immunotherapy. J Neurooncol. 2007;81:139-48.

32. Prins RM, Odesa SK, Liau LM. Immunotherapeutic targeting of shared melanoma-associated antigens in a murine glioma model. Cancer Res. 2003;63:8487-91.

33. Silbergeld DL, Rostomily RC, Alvord EC Jr. The cause of death in patients with glioblastoma is multifactorial: clinical factors and autopsyfindings in 117 cases of supratentorial glioblastoma in adults. J Neurooncol. 1991;10:179-85.

34. Aghi MK, Batchelor TT, Louis DN, Barker FG, Curry WT Jr. Decreased rate of infection in glioblastoma patients with allelic loss of chromosome 10q. J Neurooncol. 2009;93:115-20.

35. Parsa AT, Waldron JS, Panner A, et al. Loss of tumor suppressor PTEN function increases B7-H1 expression and immunoresistance in glioma. Nat Med. 2007;13:84-8

36. Hao C, Parney IF, Roa WH, Turner J, Petruk KC, Ramsay DA. Cytokine and cytokine receptor mRNA expression in human glioblastomas: evidence of Th1, Th2 and Th3 cytokine dysregulation. Acta Neuropathol. 2002;103:171-8.

37. Fecci PE, Mitchell DA, Whitesides JF, et al. Increased regulatory T-cell fraction amidst a diminished CD4 compartment explains cellular immune defects in patients with malignant glioma. Cancer Res. 2006;66:3294-302.

38. El Andaloussi A, Lesniak MS. An increase in $\mathrm{CD} 4^{+} \mathrm{CD} 25^{+} \mathrm{FOXP} 3^{+}$ regulatory $\mathrm{T}$ cells in tumor-infiltrating lymphocytes of human glioblastoma multiforme. Neurooncol. 2006;8:234-43.

39. See AP, Parker JJ, Waziri A. The role of regulatory T cells and microglia in Glioblastoma-associated immunosuppression. J Neurooncol. 2015;123:405-12.

40. Choe G, Horvath S, Cloughesy TF, et al. Analysis of the phosphatidylinositol 3'-kinase signaling pathway in glioblastoma patients in vivo. Cancer Res. 2003;63:2742-6.

41. Ermoian RP, Furniss CS, Lamborn KR, et al. Dysregulation of PTEN and protein kinase $\mathrm{B}$ is associated with glioma histology and patient survival. Clin Cancer Res. 2002;8:1100-6. 
42. Louis DN, Holland EC, Cairncross JG. Glioma classification: a molecular reappraisal. Am J Pathol. 2001;159:779-86.

43. Yang L, Ng KY, Lillehei KO. Cell-mediated immunotherapy: a new approach to the treatment of malignant glioma. Cancer Control. 2003; 10:138-47.

44. Pistoia V, Morandi F, Wang X, Ferrone S. Soluble HLA-G: Are they clinically relevant? Semin Cancer Biol. 2007;17:469-79.

45. Wiendl H, Mitsdoerffer M, Weller M. Hide-and-seek in the brain: a role for HLA-G mediating immune privilege for glioma cells. Semin Cancer Biol. 2003;13:343-51.

46. Das A, Tan WL, Teo J, Smith DR. Expression of survivin in primary glioblastomas. J Cancer Res Clin Oncol. 2002;128:302-6.

47. Gomez GG, Kruse CA. Mechanisms of malignant glioma immune resistance and sources of immunosuppression. Gene Ther Mol Biol. 2006;10:133-46.

48. Zisakis A, Piperi C, Themistocleous MS, et al. Comparative analysis of peripheral and localised cytokine secretion in glioblastoma patients. Cytokine. 2007;39:99-105.

49. Yamanaka R. Dendritic-cell- and peptide-based vaccination strategies for glioma, Neurosurg Rev. 2009;32:265-73.

50. Muragaki $\mathrm{Y}$, Maruyama $\mathrm{T}$, Iseki $\mathrm{H}$, et al. Phase $\mathrm{I} / \mathrm{II}$ trial of autologous formalin-fixed tumor vaccine concomitant with fractionated radiotherapy for newly diagnosed glioblastoma: clinical article. J Neurosurg. 2011;115:248-55.

51. Palu G, Cavaggioni A, Calvi P, et al. Gene therapy of glioblastoma multiforme via combined expression of suicide and cytokine genes: a pilot study in humans. Gene Ther. 1999;6:330-7.

52. Merchant RE, Grant AJ, Merchant LH, Young HF. Adoptive immunotherapy for recurrent glioblastoma multiforme using lymphokine activated killer cells and recombinant interleukin-2. Cancer. 1988;62:665-71.

53. Parsa A, Crane C, Wilson S, et al. Autologous tumor derived gp96 evokes a tumor specific immune response in recurrent glioma patients that correlates with clinical response to therapy. In Proceedings of the AACE-NCI-EORTC International Conference Molecular Targets and Cancer Therapeutics 2007.

54. Ampie L, Choy W, Lamano JB, Fakurnejad S, Bloch O, Parsa AT. Heat shock protein vaccines against glioblastoma: from bench to bedside. J Neurooncol. 2015;123:441-8.

55. Topalian SL, Hodi FS, Brahmer JR, et al. Safety, activity, and immune correlates of anti-PD-1 antibody in cancer. N Engl J Med. 2012;366:2443-54.

56. Wolchok JD, Kluger H, Callahan MK, et al. Nivolumab plus ipilimumab in advanced melanoma. N Engl J Med. 2013;369:122-33.

57. Ansell SM, Lesokhin AM, Borrello I, et al. PD-1 blockade with nivolumab in relapsed or refractory Hodgkin's lymphoma. N Engl J Med. 2015;372:311-9.

58. Motzer RJ, Rini BI, McDermott DF, et al. Nivolumab for metastatic renal cell carcinoma: results of a randomized phase II trial. J Clin Oncol. 2015;33:1430-7.

59. Rizvi NA, Mazières J, Planchard D, et al. Activity and safety of nivolumab, an anti-PD-1 immune checkpoint inhibitor, for patients with advanced, refractory squamous non-small-cell lung cancer (CheckMate 063): a phase 2, single-arm trial. Lancet Oncol. 2015;16:257-65.

60. Opdivo (nivolumab) [prescribing information] http://www.opdivo. bmscustomer connect.com/gateway (Bristol-Myers Squibb Company, 2014).

61. Keytruda (pembrolizumab) [prescribing information] http://www. merck.com/product/usa/pi_circulars/k/keytruda/keytruda_pi.pdf (Merck \& Co., Inc. 2015).

62. Krauze AV, Myrehaug SD, Chang MG, et al. A Phase 2 Study of Concurrent Radiation Therapy, Temozolomide, and the Histone Deacetylase Inhibitor Valproic Acid for Patients With Glioblastoma. Int J Radiat Oncol Biol Phys. 2015;92:986-92.

63. Wainwright DA, Chang AL, Dey M, et al. Durable therapeutic efficacy utilizing combinatorial blockade against IDO, CTLA-4, and PD-L1 in mice with brain tumors. Clin Cancer Res. 2014;20:5290-301.

64. Castro MG, Baker GJ, Lowenstein PR. Blocking immunosuppressive checkpoints for glioma therapy: the more the Merrier! Clin Cancer Res. 2014;20:5147-9.
65. Cohen CJ, Hoffmann N, Farago M, Hoogenboom HR, Eisenbach L, Reiter Y. Direct detection and quantitation of a distinct T-cell epitope derived from tumor-specific epithelial cell-associated mucin using human recombinant antibodies endowed with the antigen-specific, major histocompatibility complex-restricted specificity of T cells. Cancer Res. 2002;62:5835-44.

66. Denkberg G, Cohen CJ, Lev A, Chames P, Hoogenboom HR, Reiter Y. Direct visualization of distinct $\mathrm{T}$ cell epitopes derived from a melanoma tumor-associated antigen by using human recombinant antibodies with MHC- restricted T cell receptor-like specificity. Proc Natl Acad Sci. 2002;99:9421-6.

67. Cohen CJ, Sarig O, Yamano Y, Tomaru U, Jacobson S, Reiter Y. Direct phenotypic analysis of human MHC class I antigen presentation: visualization, quantitation, and in situ detection of human viral epitopes using peptide-specific, MHC-restricted human recombinant antibodies. J Immunol. 2003;170: 4349-4361.

68. Denkberg G, Klechevsky E, Reiter Y. Modification of a tumorderived peptide at an HLA-A2 anchor residue can alter the conformation of the MHC-peptide complex: probing with TCRlike recombinant antibodies. J Immunol. 2002;169:4399-407.

69. Cohen-Inbar O. Recruitment of Immune Effector Cells against Astrocytoma by MHC-chlrotoxin Chimeric Protein. PhD dissertation, Technion Israel Institute of Technology, 2014.

70. Yu JS, Wheeler CJ, Zeltzer PM, et al. Vaccination of malignant glioma patients with peptide-pulsed dendritic cells elicits systemic cytotoxicity and intracranial T-cell in-filtration. Cancer Res. 2001;61:842-7.

71. Liau LM, Prins RM, Kiertscher SM, et al. Dendritic cell vaccination in glioblastoma patients induces systemic andintracranial T-cell responses modulated by the local central nervous system tumor microenvironment. Clin Cancer Res. 2005;11:5515-25.

72. Sampson JH, Heimberger AB, Archer GE, et al. Immunologic escape after prolonged progression-free survival with epidermal growth factor receptor variant III peptide vaccination in patients with newly diagnosed glioblastoma. J Clin Oncol. 2010;28:4722-9.

73. Schneider T, Gerhards R, Kirches E, Firsching R. Preliminary results of active specific immunization with modified tumor cell vaccine in glioblastoma multiforme. J Neuro-Oncol. 2001;53:39-46.

74. Steiner HH, Bonsanto MM, Beckhove $\mathrm{P}$, et al. Antitumor vaccination of patients with glioblastoma multiforme: a pilot study to assess feasibility, safety, and clinical benefit. J Clin Oncol. 2004;22:4272-81.

75. Ishikawa E, Tsuboi K, Yamamoto T, et al. Clinical trial of autologous formalin-fixed tumor vaccine for Glioblastoma multiforme patients. Cancer Sci. 2007;98:1226-33.

76. Bogdahn U, Hau P, Stockhammer G, et al. Targeted therapy for highgrade glioma with the TGF-beta2 inhibitor trabedersen: results of a randomized and controlled phase IIb study. Neuro-Oncol. 2011;13:132-42.

77. Merchant RE, McVicar DW, Merchant LH, Young HF. Treatment of recurrent malignant glioma by repeated intracerebral injections of human recombinant interleukin-2 alone or in combination with systemic interferon- $\alpha$. Results of a phase I clinical trial. J NeuroOncol. 1992;12:75-83.

78. Barba D, Saris SC, Holder C, Rosenberg SA, Oldfield EH. Intratumoral LAK cell and interleukin-2 therapy of human gliomas. J Neurosurgery. 1989;70:175-82.

79. Colombo F, Barzon L, Franchin E, et al. Combined HSV-TK/IL-2 gene therapy in patients with recurrent glioblastoma multiforme: biological and clinical results. Cancer Gene Ther. 2005;12: 835-48.

80. Farkkila M, Jaaskelainen J, Kallio M, et al. Randomised, controlled study of intratumoral recombinant $\gamma$-interferon treatment in newly diagnosed glioblastoma. Br J Cancer. 1994;70:138-41.

81. Wolff JE, Wagner S, Reinert C, et al. Maintenance treatment with interferon-gamma and low-dose cyclophosphamide for pediatric high-grade glioma. J Neuro-Oncol. 2006;79:315-21.

82. Allen J, Packer R, Bleyer A, Zeltzer P, Prados M, Nirenberg A. Recombinant interferon beta: a phase I-II trial in children with recurrent brain tumors. J Clin Oncol. 1991;9:783-8. 
83. Fetell MR, Housepian EM, Oster MW, et al. Intratumor administration of beta-interferon in recurrent malignant gliomas. A Phase I clinical and laboratory study. Cancer. 1990;65:78-83.

84. Mahaley MS, Dropcho EJ, Bertsch L, Tirey T, Gillespie GY. Systemic beta-interferon therapy for recurrent gliomas: a brief report. J Neurosurgery. 1989;71:639-41.

85. Buckner JC, Brown LD, Kugler JW, et al. Phase II evaluation of recombinant interferon alpha and $\mathrm{BCNU}$ in recurrent glioma. J Neurosurgery. 1995;82:430-5.

86. Buckner JC, Schomberg PJ, McGinnis WL, et al. A Phase III study of radiation therapy plus carmustine with or without recombinant interferon- $\alpha$ in the treatment of patients with newly diagnosed high-grade glioma. Cancer. 2001;92:420-33.

87. Olson JJ, McKenzie E, Skurski-Martin M, Zhang Z, Brat D, Phuphanich S. Phase I analysis of BCNU-impregnated biodegradable polymer wafers followed by systemic interferon alfa- $2 \mathrm{~b}$ in adults with recurrent glioblastoma multiforme. J Neuro-Oncol. 2008;90:293-9.

88. Okada H, Lieberman FS, Walter KA, et al. Autologous glioma cell vaccine admixed with interleukin-4 gene transfected fibroblasts in the treatment of patients with malignant gliomas. J Transl Med. 2007;5:67.

89. Rand RW, Kreitman RJ, Patronas N, Varricchio F, Pastan I, Puri RK. Intratumoral administration of recombinant circularly permuted interleukin-4-Pseudomonas exotoxin in patients with highgrade glioma. Clin Cancer Res. 2000;6:2157-65.

90. Kikuchi T, Akasaki Y, Abe T, et al. Vaccination of glioma patients with fusions of dendritic and glioma cells and recombinant human interleukin 12. J Immunother. 2004;27:452-9.
91. Jacobs SK, Wilson DJ, Kornblith PL, Grimm EA. Interleukin-2 or autologous lymphokine-activated killer cell treatment of malignant glioma: phase I trial. Cancer Res. 1986;46:2101-4.

92. Lillehei KO, Mitchell DH, Johnson SD, McCleary EL, Kruse CA. Long-term follow-up of patients with recurrent malignant gliomas treated with adjuvant adoptive immunotherapy. Neurosurgery. 1991;28:16-23.

93. Hayes RL, Koslow M, Hiesiger EM, et al. Improved long term survival after intracavitary interleukin-2 and lymphokineactivated killer cells for adults with recurrent malignant glioma. Cancer. 1995;76:840-52.

94. Dillman RO, Duma CM, Schiltz PM, et al. Intracavitary placement of autologous lymphokine-activated killer (LAK) cells after resection of recurrent glioblastoma. J Immunother. 2004;27: 398-404.

95. Tsurushima H, Liu SQ, Tuboi K, et al. Reduction of end-stage malignant glioma by injection with autologous cytotoxic T lymphocytes. Jap J Cancer Res. 1999;90:536-45.

96. Plautz GE, Miller DW, Barnett GH, et al. T cell adoptive immunotherapy of newly diagnosed gliomas. Clin Cancer Res. 2000;6:2209-18.

97. Jackson C, Ruzevick J, Phallen J, Belcaid Z, Lim M. Challenges in Immunotherapy Presented by the Glioblastoma Multiforme Microenvironment. Clin Dev Immunol. 2011;2011:732413, doi: 10.1155/2011/732413. Epub 2011 Dec 10.

98. Caruso JP, Cohen-Inbar O, Bilsky MH, Gerszten PC, Sheehan JP. Stereotactic radiosurgery and immunotherapy for metastatic spinal melanoma. Neurosurg Focus. 2015;38:E6. 